\title{
Review on different Meta-Heuristic Techniques for Parallel Computing
}

\author{
Davinderjit Kaur \\ Department of Computer Engineering and \\ Technology \\ Guru Nanak Dev University \\ Amritsar, India
}

\author{
Amit Chabbra \\ Department of Computer Engineering and \\ Technology \\ Guru Nanak Dev University \\ Amritsar, India
}

\begin{abstract}
This paper represents the parallel computing is a type of working out through which many data or the execution connected with processes are finished concurrently as well as scheduling along with source of information permitting so that we can optimize efficiency standards within multi-cluster heterogeneous situations is acknowledged for NP-hard problems. Multi-cluster environments are commonly represented as a substitution to high-performance computing regarding resolving large-scale search engine optimization difficulties. The review has shown the various meta heuristic techniques which has proved their usefulness to find the optimum schedule around large-scale allocated circumstances. It also shows the comparison of Meta heuristic techniques which evaluates the real workload trace as well as shows the advantages and disadvantages when it comes to other wellknown approaches outlined inside literature.
\end{abstract}

\section{Keywords}

Parallel computing, multi-clusters, co-allocation, metaheuristics

\section{INTRODUCTION}

\subsection{Parallel Computing}

Parallel computing is a type of computation in which many calculations or the execution of processes are carried out simultaneously. The term parallel computing" refers to the simultaneous execution of processes. Large problems are divided into sub-problems and then these sub-tasks are executed simultaneously. Parallel computing is closely associated with concurrent computing they may be used in concert, and sometimes conflated, although 2 are distinct: you'll be able to have parallelism with no concurrency (such due to the fact bit-level parallelism), in addition to concurrency devoid of parallelism (such due to the fact multitasking by means of time-sharing on the single-core CPU) The outcomes of such sub-tasks are after that put together about completion. How much parallelism is different from dilemma in order to problem. Fig. 1 indicates your allowance associated with parallel work in order to processor.

\section{Parallel Computing}

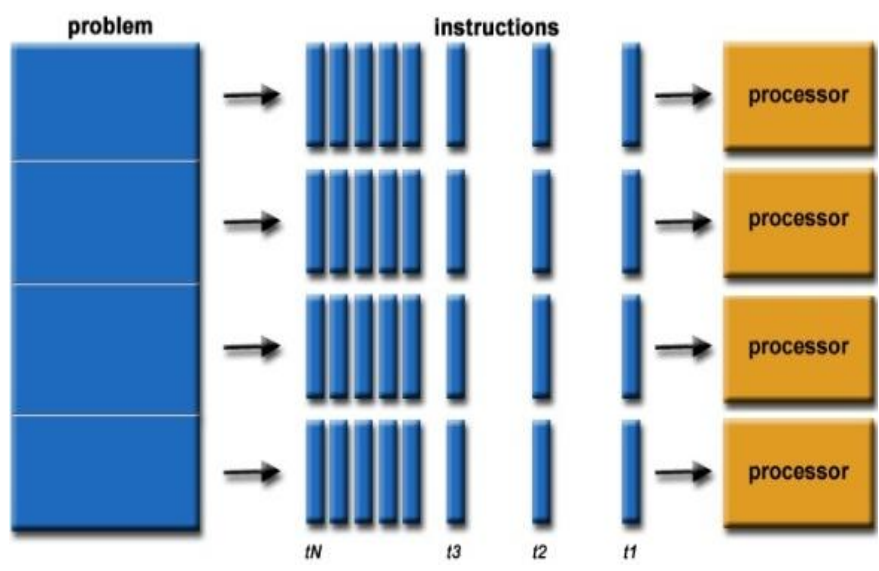

Fig. 1: Allocation of parallel tasks to processors

\subsection{Scheduling}

Scheduling means to determine the order of job execution, which job will execute on which machine within the specified time period. It is one of the crucial step to improve the system performance. If scheduling not done properly, it can lead to degradation of system performance. Basically, scheduling problem allows scheduling of tasks on resources subjected to certain constraints to optimize given objective function.

Phases of scheduling: While scheduling jobs, the scheduler performs the following steps:

1. Information gathering of tasks.

2. Selecting resources

3. Planning

4. Allocating resources according to planning

5. Monitoring

\subsection{Multi-Clusters}

Cluster is a collection of computing machines. Thus, multicluster environment consists of multiple clusters acting collectively, to treat the problems whose requirement is more than available resources. Thus, the parallel tasks are distributed across cluster boundaries. 


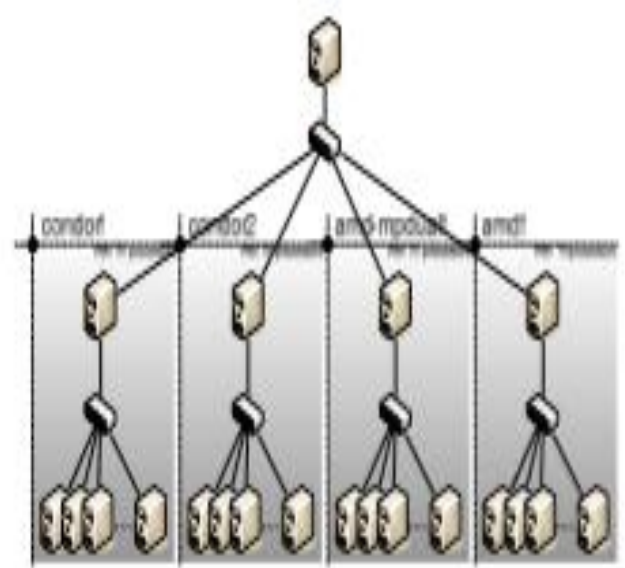

Fig. 2: A multi-cluster environment

\subsection{Co-allocation}

It is the entire process of allocating sources through multiple providers. It usually is called synchronized gain access to connected with multiple resources. It can maximize the job throughput by reducing the queue waiting time. On unavailability of resources in a particular cluster, the scheduler allocate the tasks across different clusters. This kind of allocation strategy is referred to as co-allocation of jobs.

\subsection{Phases of scheduling in grids}

In order to perform the scheduling process, the Grid scheduler has to follow a series of steps which could be classified into five blocks

1) Preparation and information gathering on tasks, jobs or applications submitted to the Grid.

2) Resource selection.

3) Computation of the planning of tasks to selected resources.

4) Task allocation according to the planning (the mapping of tasks to selected resources) Monitoring of task.

\section{META HEURISTICS}

Some of the scheduling problems in parallel computing belong to the category referred to as NP very difficult problems. To get these types of issues it is not possible to find exact solution, so we look for an sub-optimal solution. Meta heuristics help us to solve these problems to achieve suboptimal solutions. Some of the meta-heuristics are discussed below:

\subsection{Ant Colony Optimization}

Ant colony optimization is definitely an algorithm based on the behavior of ants searching shortest path between food source and colonies. While walking to food source from colonies, the ants leave pheromones on their way. The amount of pheromone on the way keeps on increasing with the number of ants passing but decreases with pheromone evaporation.

1) Usage

2) Searching shortest route

3) Job-shop scheduling

4) Task scheduling in grids etc.

\subsection{Genetic Algorithm}

It was introduced in 1975 by Holland. It is based on evolution process in nature. Each chromosome represents solution to problem. The initial population is randomly taken. At each step, the value of the objective function is examined by applying crossover as well as mutation operations. At each step, new off springs are generated.

\subsection{BAT algorithm}

Bat algorithm seemed to be encouraged from the replicate position behavior of micro bats, along with pulse rates with emission and loudness. Bat algorithm got its start through Xin-She Yang in 2010. Just about every virtual bat travels arbitrarily by using a rate ' $v$ ' at situation (solution) ' $\mathrm{x}$ ' by using a diverse rate or even wave length and loudness. Since it looks and finds its prey, the item alterations rate, loudness and pulse emission rate, research is definitely more intense using a neighborhood random walk. Choice of the finest remains until eventually a number of halt standards usually is met.

\subsection{Firefly algorithm}

This technique is actually a Meta heuristic offered by Xin-She Yang and encouraged with the pulsating behavior with fireflies. The major purpose for a firefly's flash is to work as a transmission method to draw different fireflies. Xin-She Yang created this specific firefly formula through assuming:

1) Most fireflies usually are unisexual, to ensure that every firefly might be attracted to all the other fireflies.

2) Attraction is actually proportional to their lighting, and for any pair of fireflies, much less bright may be fascinated through and shift towards brighter one; nevertheless, this intensity decreases as the mutual range grows.

3) In the case there aren't any fireflies lighter than a given firefly, it will move in random direction.

This lighting ought to be connected with objective function.

\subsection{Cuckoo algorithm}

It is a meta-heuristic technique proposed by Xin-she Yang in 2009. It turned out to be motivated by the obligate generation parasitism associated with a few cuckoo species by simply laying the eggs inside nests associated with another host birds . Many host birds might indulge one on one struggle together with the intruding cuckoos. Such as, if the host bird finds this egg usually are not their own personal, it will eventually throw these unfamiliar eggs apart or perhaps get away from its nest and make a whole new nesting elsewhere.

\subsection{ABC algorithm}

Artificial Bee Colony (ABC) algorithm is usually a swarm cleverness based character inspired algorithm that has been designed by Karaboga regarding multi-modal in addition to multi- dimensional numeric problems. $\mathrm{ABC}$ attempts to design all-natural practices regarding actual honey bees with foodstuff foraging. Honey bees use quite a few systems including waggle dancing in order to perfectly identify foodstuff solutions in addition to locate new ones.

\section{LITERATURE SURVEY}

Dhananjay Thiruvady et al. (2014) within this study, your biobjective booking problem with flexible running functions about similar related equipment can be investigated. principally encouraged because of the use in the just-in-time 
(JIT) doctrine about similar related equipment concerning biobjective system. M. H. Fazel Zarandi et al (2014) within this study, your bi-objective booking problem with flexible running functions about similar related equipment can be investigated. principally encouraged because of the use in the just-in-time (JIT) doctrine about similar related equipment concerning bi-objective system, anywhere the work running functions are usually controllable. related internet achieve compression-net achieve expansion" (BPNBC-NBE) heuristic. Furthermore, your plan connected with occupations about every unit, by using power connected with running most occupations, can be determined. Sid Ahmed et.al(2011)[3] proposed that computational plants made available this computational plants have the possibility intended for sorting large-scale scientific troubles selecting heterogeneous yellow-colored crushed lime stone geographically distributed resources with Service (QoS) intended for lines customers would be the useful co-allocation connected with jobs. Because of the attractive undertake a coallocation system that will not depend on a use of coherent international information. Pierre Delisle et. al (2004)[4] presents a parallel implementation of an ant colony optimization Met heuristic for the clear answer of a commercial arrangement issue in a metal casting center. this approach, along with Met heuristics in general, presents good quality of option, it still needs substantial computational time and resources. The code is prepared in D and the application form has been accomplished on a Silicon Artwork Source 2000 similar machine. Gerald Sabi (2003) [5] sorted out the actual arranging involving parallel jobs opportunities in the heterogeneous multi-site natural environment, nevertheless processors from distinct web pages possess distinct speeds. Starting up with a basic greedy arranging approach, many of us propose to your girlfriend and also examine quite a few enhancements applying track operated simulations..KuoChing Ying et al.(2011) [6] put up with all the not related parallel machine arrangement challenge with sequence- and also machine-dependent set up periods below deadline limitations, a key subject for a number of manufacturing applications. ABC protocol is definitely analyzed through contrasting it is alternatives along with that regarding state-ofthe-art algorithms for the identical typical issue set. Computational benefits show that the particular involve ABC protocol significantly outperforms pre-existing algorithms for the majority of issue combinations.Marcus Randall ainsi que (2002) [7] Ant Community Optimization is a reasonably brand new group involving meta-heuristic look for methods with regard to promoting problems. Because it's a person's population-based technique that may inspects quite a few solution options essentially phase from the criteria, there are numerous involving parallelization opportunities. quite a few identical deteriorating tactics are often examined. Gerald Sabi (2003) [8] most earlier analysis for work scheduling with regard to heterogeneous devices considers a position the place every work or maybe task is actually mapped to a individual process. Eloi Gabaldon et al(2016).[9] suggested that after the free sources happen to be configured, completely new possibilities occur intended for cutting down power utilization by giving ideal matching of parallel programs to free computing nodes. Eloi Gabaldon et al.(2016) [10] proposed a genetic algorithm for organizing job-packages connected with parallel jobs for source federated environments. With regards to proposition seemed to be to determine the task schedule and also offer allocation to enhance the application operation and also process throughput.

\section{COMPARISON TABLE}

Table 1. Comparison table of different meta heuristic techniques

\begin{tabular}{|c|c|c|c|c|}
\hline $\begin{array}{l}\text { Name of } \\
\text { Author }\end{array}$ & Title of paper & Technique & Advantages & Disadvantages \\
\hline $\begin{array}{l}\text { Gabaldon } \\
\text { (2016) }\end{array}$ & $\begin{array}{l}\text { Blacklist muti-objective } \\
\text { genetic algorithm for } \\
\text { energy saving in } \\
\text { heterogeneous } \\
\text { environments }\end{array}$ & $\begin{array}{l}\text { A Genetic algorithm } \\
\text { based on weighted } \\
\text { blacklist }\end{array}$ & $\begin{array}{l}\text { Supports multi- } \\
\text { objective } \\
\text { Easily distributed }\end{array}$ & $\begin{array}{l}\text { Slow convergence } \\
\text { speed. } \\
\text { Works on local optima. }\end{array}$ \\
\hline $\begin{array}{l}\text { Gabaldon } \\
\text { (2015) }\end{array}$ & $\begin{array}{l}\text { Slowdown-Guided } \\
\text { Genetic Algorithm for Job } \\
\text { Scheduling in Federated } \\
\text { Environments }\end{array}$ & Genetic algorithm & $\begin{array}{l}\text { Works on global } \\
\text { optima. } \\
\text { Uses few parameters }\end{array}$ & $\begin{array}{l}\text { Suffers from pre-mature } \\
\text { convergence. }\end{array}$ \\
\hline $\begin{array}{l}\text { Hector } \\
\text { Blanco(2012) }\end{array}$ & $\begin{array}{l}\text { MIP model scheduling for } \\
\text { multi-clusters }\end{array}$ & $\begin{array}{l}\text { MIP-based } \\
\text { scheduling }\end{array}$ & Inherent parallelism. & $\begin{array}{l}\text { Works on local optima. } \\
\text { Sequence of random } \\
\text { decisions. }\end{array}$ \\
\hline $\begin{array}{l}\text { Alejandro } \\
\text { Acosta(2010) }\end{array}$ & $\begin{array}{l}\text { Dynamic load balancing } \\
\text { on heterogeneous } \\
\text { multicore/multiGPU } \\
\text { systems }\end{array}$ & $\begin{array}{l}\text { Dynamic load } \\
\text { balancing }\end{array}$ & $\begin{array}{l}\text { Automatic sub- } \\
\text { division. } \\
\text { Potential of coping } \\
\text { with multimodality. }\end{array}$ & $\begin{array}{l}\text { Gets struck into many } \\
\text { local optima's. } \\
\text { Doesn't memorize } \\
\text { history of better } \\
\text { solutions. }\end{array}$ \\
\hline
\end{tabular}




\begin{tabular}{|l|l|l|l|l|}
\hline $\begin{array}{l}\text { Sid Ahmed } \\
\text { Makhlouf } \\
(2011)\end{array}$ & $\begin{array}{l}\text { Resources Co-allocation } \\
\text { Strategies in Grid } \\
\text { Computing }\end{array}$ & $\begin{array}{l}\text { Co-allocation } \\
\text { strategy }\end{array}$ & $\begin{array}{l}\text { Fast convergence at } \\
\text { very early stage. }\end{array}$ & $\begin{array}{l}\text { In the case BA changes } \\
\text { to exploitation phase too } \\
\text { rapidly, that may cause } \\
\text { stagnation after some } \\
\text { initial stage. }\end{array}$ \\
\hline $\begin{array}{l}\text { Kuo Chang } \\
\text { Huang(2010) }\end{array}$ & $\begin{array}{l}\text { Processor allocation } \\
\text { policies for reducing } \\
\text { resource fragmentation in } \\
\text { multi-cluster grid and } \\
\text { cloud environments }\end{array}$ & $\begin{array}{l}\text { Most-fit co-allocation } \\
\text { policy }\end{array}$ & $\begin{array}{l}\text { Fast convergence } \\
\text { speed. } \\
\text { Global optima }\end{array}$ & $\begin{array}{l}\text { Selection of initial } \\
\text { cuckoos }\end{array}$ \\
\hline $\begin{array}{l}\text { Gerald } \\
\text { Sebi(2003) }\end{array}$ & $\begin{array}{l}\text { Scheduling of parallel } \\
\text { jobs in a heterogeneous } \\
\text { multi-site environment }\end{array}$ & $\begin{array}{l}\text { Greedy scheduling } \\
\text { strategy }\end{array}$ & $\begin{array}{l}\text { We consider the use of } \\
\text { multiple simultaneous } \\
\text { reservations at } \\
\text { different sites }\end{array}$ & $\begin{array}{l}\text { Doesn't memorize } \\
\text { history of better } \\
\text { solutions. }\end{array}$ \\
\hline Shih Wei(2012) & $\begin{array}{l}\text { Hybrid ABC for unrelated } \\
\text { machines }\end{array}$ & Hybrid ABC & $\begin{array}{l}\text { machine-dependent } \\
\text { setup times under due } \\
\text { date constraints, }\end{array}$ & $\begin{array}{l}\text { practical ABC } \\
\text { algorithms useful in } \\
\text { scheduling problems }\end{array}$ \\
\hline
\end{tabular}

\section{CONCLUSION}

The organizing with concurrent jobs in the heterogeneous multi-site setting, in which just about every website features a homogeneous cluster with processors, however processors in distinct web pages provides distinct speeds. However, the time cost of they causes them to be incorrect pertaining to large-scale environments. In this report this shows the many Meta heuristic techniques for concurrent job scheduling. The review in parallel job scheduling has applied various metaheuristic techniques for scheduling of jobs but it suffers from local optima problem. Moreover convergence speed of genetic algorithm is slow so it takes more time to give final results. In future a hybridized approach of meta-heuristics will be introduced for scheduling of parallel jobs to optimize the make span and flow time of parallel jobs.

\section{REFERENCES}

[1] Dhananjay Thriuvady, et al "Parallel ant colony optimization for resource constrained job scheduling". Springer (2014).

[2] Piotr Swistalski, et al "Scheduling parallel batch jobs in grids with evolutionary Metaheuristics". Springer (2014).

[3] Makhlouf, Sid Ahmed, and Belabbas Yagoubi. "Resources Co-allocation Strategies in Grid Computing." CIIA. 2011.

[4] Randall, Marcus, and Andrew Lewis. "A parallel implementation of ant colony optimization." Journal of Parallel and Distributed Computing 62.9 (2002): 14211432.

[5] Huang, Kuo-Chan, and Kuan-Po Lai. "Processor allocation policies for reducing resource fragmentation in multi-cluster grid and cloud environments." Computer Symposium (ICS), 2010 International. IEEE, 2010.

[6] Sabin, Gerald, et al. "Scheduling of parallel jobs in a heterogeneous multi-site environment." Workshop on Job Scheduling Strategies for Parallel Processing. Springer Berlin Heidelberg, 2003.
[7] Gabaldon, Eloi, Josep Lluis Lerida, Fernando Guirado, and Jordi Planes. "Blacklist muti-objective genetic algorithm for energy saving in heterogeneous environments." The Journal of Supercomputing (2016): $1-16$.

[8] Gabaldon, Eloi, et al. "Particle Swarm Optimization Scheduling for Energy Saving in Cluster Computing Heterogeneous Environments." Future Internet of Things and Cloud Workshops (FiCloudW), IEEE International Conference on. IEEE, 2016.

[9] Gabaldon, Eloi, et al. "Slowdown-Guided Genetic Algorithm for Job Scheduling in Federated Environments." International Conference on Nature of Computation and Communication. Springer International Publishing, 2014.

[10] Blanco, H., Guirado, F., Lérida, J. L., \& Albornoz, V. M. (2012, August). MIP model scheduling for multiclusters. In European Conference on Parallel Processing (pp. 196-206). Springer Berlin Heidelberg.

[11] Bolaji, A. L. A., Khader, A. T., Al-Betar, M. A., \& Awadallah, M. A. (2013). Artificial bee colony algorithm, its variants and applications: A survey. Journal of Theoretical \& Applied Information Technology, 47(2).

[12] Acosta, Alejandro, et al. "Dynamic load balancing on heterogeneous multicore/multiGPU systems." High Performance Computing and Simulation (HPCS), 2010 International Conference on. IEEE, 2010.

[13] Makhlouf, Sid Ahmed, and Belabbas Yagoubi. "Resources Co-allocation Strategies in Grid Computing." CIIA. 2011.

[14] Huang, Kuo-Chan, and Kuan-Po Lai. "Processor allocation policies for reducing resource fragmentation in multi-cluster grid and cloud environments." Computer Symposium (ICS), 2010 International. IEEE, 2010. 
[15] Sabin, Gerald, et al. "Scheduling of parallel jobs in a heterogeneous multi-site environment." Workshop on Job Scheduling Strategies for Parallel Processing. Springer Berlin Heidelberg, 2003.

[16] Acosta, Alejandro, et al. "Dynamic load balancing on heterogeneous multicore/multiGPU systems." High Performance Computing and Simulation (HPCS), 2010 International Conference on. IEEE, 2010.

[17] Ernst, Andreas T., and Gaurav Singh. "Lagrangian particle swarm optimization for a resource constrained machine scheduling problem." 2012 IEEE Congress on Evolutionary Computation. IEEE, 2012.

[18] Ying, Kuo-Ching, and Shih-Wei Lin. "Unrelated parallel machines scheduling with sequence-and machine- dependent setup times and due date constraints." International Journal of Innovative Computing, Information and Control 8.5 (2012): 3279-3297.

[19] Blanco, Héctor, et al. "Multiple Job Allocation in

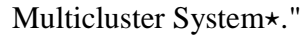

[20] Fister Jr, Iztok, Dušan Fister, and Iztok Fister. "A comprehensive review of cuckoo search: variants and hybrids." International Journal of Mathematical Modelling and Numerical Optimisation 4.4 (2013): 387 409.

[21] Kalra, Mala, and Sarbjeet Singh. "A review of metaheuristic scheduling techniques in cloud computing." Egyptian Informatics Journal 16.3 (2015): 275-295. 